9. Production of the effector cytokine interleukin-17, rather than interferon- $\gamma$, is more strongly associated with autoimmune hemolytic anemia / A. M. Hall, O. M.Zamzami, N. Whibley [etal.]//Haematologica. 2012. - Vol. 97, № 10. - P. 1494-1500.

10. The study of IL-18 and IL-18 BP balance in aplastic anemia / N. N. Shan, Y.J. Jiang, X. H. Sui [et al.] // Infect. Immun. - 2011. - Vol. 32, № 11. - P. 783-785.

11. Th17 immune responses contribute to the pathophysiology of aplastic anemia / R. P. de Latour,
V. Visconte, T. Takaku [et al.] // Blood. - 2010. Vol. 116. - P. 4175-4184.

12. Role of IL-10 for Induction of Anemia During Inflammation / H. Tilg, H. Ulmer, A. Kaser [et al.] // J. Immunol. - 2002. - Vol. 169, № 4. - P. 22042209.

Надійшла до редакиії 15.02.2014

Прийнята до друку 27.03.2014

(C) Кундін В. Ю., 2014

УДК: 616.61-002.3-053.2:[616.61-008-073:57.088.6

\title{
В.Ю. КУНДІН
}

\section{КОМПЛЕКСНА РАДІОНУКЛІДНА ОЦІНКА СТРУКТУРНО-ФУНКЦІОНАЛЬНОГО СТАНУ СДИНОЇ НИРКИ В ДІТЕЙ}

\section{KUNDIN \\ COMPLEX RADIONUCLIDE EVALUATION OF STRUCTURAL AND FUNCTIONAL STATE OF THE SINGLE KIDNEY IN CHILDREN}

ДУ «Інститут серця МОЗ України», Київ

\author{
Institute heart, Ministry of health of Ukraine
}

\begin{abstract}
Ключові слова: єдина нирка, сцинтиграфія нирок, непряма радіонуклідна ангіографія, динамічна реносцинтиграфія, статична реносцинтиграфія, нефротропні радіофармпрепарати, діти .

Keywords: single kidney, renal scintigraphy, indirect radionuclide angiography, dynamic renoscintigraphy, static renoscintigraphy, nephrotrophic radiopharmaceuticals, children.

Резюме. Введение. Цельработы определитьособенности функционирования единственной почки (еn) прикомплексныхсцинтиграфическихисследованияхсиспользованиемнефротропныхрадиофармпрепаратов (нрфn) разного механизма элиминации и определение их диагностической значимости.

Материал и методы. Динамическая (дрсг) и статическая (срсг) сцинтиграфия с ангиографией проведена у 90 детей $c$ еп в возрасте от 5 до 16 лет. Всего проведено 150 сиинтиграфий: $c$ ${ }^{99 m}$ tc-дтпа (диэтилентриаминопентацетат) - 51, с ${ }^{99 m} t c-n \phi$ (пирофосфрат) - 40, c 99m tс-дмса (диметиленсукцинатацетат) - 34, ${ }^{99 m}$ tс-таг3 (меркаптоацетилтриглицин) -15 и ${ }^{99 m} t c-э и$, (этилендицистеин) - 10. Определяля временные параметры почечного кровотока, временные параметры транспорта нрфи, скф и эпп. Контрольную группу составили 15 детей.
\end{abstract}

Результаты. Основными сцинтиграфическими признаками еп являются: наличие одной почки на сцинтиграфическом изображении; замедление временних параметров почечной гемодинамики, увеличение скорости клубочковой фильтрации (скф) и эффективного почечного плазмотока (эпn) еп на 50-60\%; уменьшение стандартизованных параметров скф и эпп на 40-50\%. Замедление экскреторной способности еп связано с задержкой нрфп в паренхиме. Размеры еп увеличены в среднем на 2-3 см, площадь сцинтиграфического изображения на 40\%. Основной тип ренографической кривой у детей с еп - паренхиматозный, который регистрируется у 50\% больных. Накопление и распределение нрфп в еп у 73,3\% пациентов - относительно равномерное.

Выводы. Таким образом, еп у детей функционирует в напряженном режиме всех компенсаторных механизмов, обеспечивающих очищение крови от продуктов жизнедеятельности, о чем свидетельствует замедление всех основных параметров ее функциональной способности.

Summary. Introduction. The aim of the work is the determination of functioning of the single kidney $(S K)$ by complex scintigraphic research with using nephrotrophic radiopharmaceuticals (NRP) of different mechanisms

Кундін Валерій Юрійович kundin@ukr.net of elimination and the detection of its diagnostic significance.

Materials and methods. 90 children (range 5-16 years) with $S K$ were examined: dynamic (DRSG) and static (SRSG) scintigraphy with angiography was made 
them. 150 scintigraphic examinations with different NRP were made: ${ }^{99 m} T c-D T P A$ (diethyleneaminopentacetate) - 51, ${ }^{99 m} T c-P P$ (pyrophosphate) - 40, ${ }^{99 m} T c-D M S A$ (dymethylenesuccinateacetate) - 34, ${ }^{99 m}$ Tc MAG3 (mercaptoacetyle-3-glycine) - 15, ${ }^{99 m}$ Tc-EC (ethylenedicysteine) - 10. Time options of renal blood flow and transport of NRP, SGF, ERP were determined. Control group consists of 15 children.

Results. The main scintigraphic features of SK are: presence of single kidney on scintigraphic image; slowdown of time options of renal haemodynamic, increasing of SGF and ERP of SK on 50-60\%; decreasing of standard parameters SGF and ERP on 40-50\%. The slowdown of SK excretion ability is associated with retention NRP in parenchyma. Proportions of SK increase on 2-3 sm average, and size of scintigraphic picture - on 40\%. The main type of renographic curve in children with $S K$ is parenchymatose, and it is found in $50 \%$ of patients. The accumulation and distribution of NRP in SK in 73,3\% is quite uniform.

Conclisions. Thus, SK in children functions in strain way of all compensation mechanisms that provide blood purification from products of vital functions, which shows the slowdown of main options of the SK functioning.

ВСТУП. Пацієнти з єдиною ниркою $(\mathrm{EH})$ привертають особливу увагу лікарів різних спеціальностей. Поширеність $\mathrm{CH}$ серед уроджених аномалій сечової системи складає від $0,7 \%$ до $0,9 \%[1,2]$. Крім того, $Е \mathrm{H}$ зустрічається у хворих з важким однобічним ураженням нирки, в результаті якого вона перестала функціонувати або була вилучена і друга нирка може бути також схильна до аналогічного захворювання [8]. Складні компенсаторні процеси в $\mathrm{EH}$ вимагають ретельного спостереження, особливо після проведення нефректоміі. Така тактика необхідна для визначення початку патологічних змін або ï прогресування [3]. Усі пацієнти з $\mathrm{EH} \mathrm{-} \mathrm{люди}$ з обмеженим резервом компенсаторних можливостей. $€ \mathrm{H}$ не спроможна повністю компенсувати відсутність другої нирки. Наявність патології найчастіше встановлюється за допомогою УЗД. При цьому нирка збільшена в розмірах, паренхіма іiі потовщена [7]. Радіонуклідні динамічні спостереження за хворими з $\mathrm{EH}$ в урології практично не проводяться. Функціональний стан і адаптацію $\mathrm{EH} \mathrm{у} \mathrm{дітей} \mathrm{оцінюють} \mathrm{у} \mathrm{більшості} \mathrm{ви-}$ падків за клініко-лабораторними даними, але цього недостатньо для адекватної оцінки і значимого динамічного спостереження [1]. Динамічну реносцинтиграфію (ДРСГ) застосовують у випадку розвитку клініко-лабораторних проявів, хоча при даній патології потрібно постійно проводити такі дослідження. Від правильного спостереження за такими дітьми, оцінки функціонального стану $\mathrm{EH}$, обраної тактики ведення хворих залежать прогноз і якість подальшого життя дитини. Діагностичні підходи у хворих 3 $\mathrm{EH}$ мають свої особливості, які треба враховувати лікарю-радіологу.

МЕТОЮ нашої роботи було визначення особливостей функціонування $\mathrm{EH}$ при комплексних сцинтиграфічних дослідженнях із використанням РФП різного механізму елімінації та визначенням їх діагностичної значущості.

МАТЕРІАЛ I МЕТОДИ. Радіонуклідні дослідження проведені 90 дітям з єдиною уродженою ниркою у віці від 5 до 16 років. Середній вік обстежених складав $10,9 \pm 3,6$ роки. Всього проведено 134 сцинтиграфії. Непряма радіонуклідна ренангіографія (НРАГ) проведена 54 хворим:
3 них 3 99mТс-ДТПО (діетилентриамінопентао-

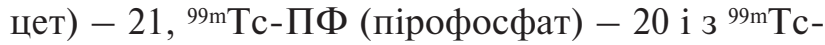
ДМСО - 13 хворим. ДРСГ проведена 75 хворим 3 них: $3^{99 m}$ Тс-МАГЗ (меркаптоацетилтригліцин) - 15 хворим $(16,7 \%), 3^{99 \mathrm{~m}}$ Тс-ЕЦ (етилендіцистеїн ) 10 хворим $(11,1 \%)$, 3 99m Тс-ДТПО - 30 хворим $(33,3 \%)$ і $3{ }^{99 \mathrm{~m}} \mathrm{Tc}-П Ф-20$ хворим $(22,2 \%)$. Динамічна і статична реносцинтиграфія (СРСГ) $3^{99 \mathrm{~m} T c-Д М С О ~(д і м е т и л е н с у к ц и н а т о ц е т) ~ п р о в е-~}$ дені 15 хворим (16,7\%). Сцинтиграфічні дослідження проводили на гамма-камері ОФЕКТ-1 3 використанням основних нефротропних радіофармпрепаратів (НРФП) - 99m Тс-ДТПО, 99m Тc-ПФ, ${ }^{99 \mathrm{~m}}$ Тс-МАГ $3,{ }^{99 \mathrm{~m}}$ Тс-ЕЦ i ${ }^{99 \mathrm{~m}}$ Тс-ДМСО. Активність НРФП розраховували на масу і площу тіла пацієнта і вона знаходилась в межах 1-2 МБк/кг залежно від виду НРФП. Променеві навантаження не виходили за межі гранично припустимих. Радіонуклідні дослідження були представлені НРАГ, ДРСГ та СРСГ. НРАГ виконувалася в сполученні із ДРСГ. Режим запису інформації складався з двох етапів: НРАГ - 30с та ДРСГ - 20 хв (експозиція - 1 кадр за 1 хв). НРАГ в спролученні із ДРСГ проводили 3 99m Тс-ДТПО і $99 \mathrm{~m}$ Тс-ПФ. В самостійному варіанті ДРСГ проводили з канальцевими НРФП - 99mТсМАГЗ $\mathrm{i}$ 99mТс-ЕЦ протягом 20 хвилин 31 кадр за $30 \mathrm{c}[4,9]$.

При НРАГ оцінювали часові параметри ниркового кровотоку:

1. Та - час артеріальної фази (c).

2. Тв - час венозної фази (c).

3. АРТ - час аорто-ренального транзиту (c).

При ДРСГ із клубочковими РФП (ДТПО і ПФ) визначали такі функціональні параметри:

1. Тмах - час максимального накопичення РФП в нирках (хв).

2. Т1/2мах - час напіввиведення РФП з ниpоK (хв).

3. $\mathrm{E}_{20}$ - відсоток виведення РФП до 20-ї хвилини дослідження (\%).

4. Швидкість клубочкової фільтрації (ШКФ) - окрема на $\Theta H$, стандартизована (мЛ/хв). 
При ДРСГ із канальцевими РФП (МАГЗ і ЕЦ) визначали такі функціональні параметри:

1. Тмах - час максимального накопичення РФП в нирках (хв).

2. Т1/2мах - час напіввиведення РФП з нирок (хв).

3. $\mathrm{E}_{20}$ - відсоток виведення РФП до 20-ї хвилини дослідження (\%).

4. Ефективний нирковий плазмоток (ЕНП) - окремий на $\mathrm{EH}$, стандартизований (мл/хв).

Длявизначенняструктурно-функціональних змін в $\mathrm{EH}$ проводили динамічну і статичну сцинтиграфію з ${ }^{99 \mathrm{~m} T c-Д М С О . ~ Д и н а м і ч н у ~ с ц и н-~}$ тиграфію 3 99m Тс-ДМСО проводили протягом 30 хв із режимом запису інформації 1 кадр за 1 хв. Статичну сцинтиграфію проводили через 2 години після введення 99m Тс-ДМСО в чотирьох проекціях: передня, задня, права та ліва бокові із розрахунком абсолютної (відсоток включення РФП в нирку) [5]. Контрольну групу склали 15 дітей відповідного віку з дизметаболічними нефропатіями без порушення функції нирок. За умовну здорову нирку була взята одна нирка 3 цієї контрольної групи.

ОТРИМАНІ РЕЗУЛЬТАТИ ТА ЇХ ОБГОВОРЕННЯ. При $\mathrm{EH} \mathrm{Та} \mathrm{і} \mathrm{Тв} \mathrm{вірогідно} \mathrm{відрізня-}$ лись від параметрів умовно здорової нирки, що свідчило про помірне уповільнення часових параметрів артеріального і венозного кровотоків в $\mathrm{EH}$, незалежно від застосованого РФП (табл.1). У хворих з $\mathrm{CH}$ в більшій мірі страждав венозний відтік, що свідчило про венозну недостатність в умовах гіпертрофічних змін в нирці.

Таблиця 1

Середні значення основних параметрів НРАГ при сцинтиграфії нирок $3^{99 \mathrm{~m}}$ Тс-ДТПО, ${ }^{99 \mathrm{~m}} \mathrm{Tc}-П Ф ~ \mathrm{i}{ }^{99 m}$ Тс-ДМСО при СН у дітей $(\mathrm{M} \pm \mathrm{m})$

\begin{tabular}{|c|c|c|c|c|}
\hline \multirow{2}{*}{ Параметри } & \multicolumn{3}{|c|}{ Радіофармпрепарат } & Контрольна група \\
\hline & ${ }^{99_{m}}$ Тс-ДТПО (n=21) & ${ }^{99 m}$ Tc-ПФ $(\mathrm{n}=\mathbf{2 0})$ & ${ }^{99 m}$ Тс-ДМСО $(n=13)$ & $(n=15)$ \\
\hline Ta (c) & $6,9 \pm 0,4^{*}$ & $6,7 \pm 0,5^{*}$ & $7,0 \pm 0,6^{*}$ & $5,6 \pm 0,3$ \\
\hline Тв (c) & $7,2 \pm 0,5^{* *}$ & $8,1 \pm 0,8^{* *}$ & $8,0 \pm 0,4 * *$ & $4,8 \pm 0,3$ \\
\hline APT (c) & $6,2 \pm 0,5$ & $6,5 \pm 0,8$ & $6,6 \pm 0,7$ & $5,8 \pm 0,3$ \\
\hline
\end{tabular}

* - відміна між дослідженою групою і контролем вірогідна, $\mathrm{p}<0,05$

** - відміна між дослідженою групою і контролем вірогідна, $\mathrm{p}<0,001$

При аналізі даних ДРСГ з 99m Тс-ДТПО (табл.2) у хворих з $\mathrm{CH}$ всі параметри, що характеризують фільтраційні процеси вірогідно відрізнялись від параметрів умовно здорової нирки. Так, окрема ШКФ ЄН складала 68,1 \pm 4,8 мл/ хв., що майже на $50 \%$ є збільшеним для окремої нирки, тоді як ШКФСт складала $86,0 \pm 4,8$ мл/ хв., що на $40 \%$ є зменшеним від норми. Таким чином, фільтрація в $\mathrm{CH} є$ збільшеною як ком- пенсаторний процес, що має забезпечити доволі пристойне очищення крові, але в цілому для організму дитини є зменшеною. За даними деяких авторів, $\mathrm{EH} \mathrm{компенсує} \mathrm{80 \%} \mathrm{фільтраційної}$ здатності двох нирок [6]. Наші дані дають дещо нижчі значення ШКФСт і вони отримані на підставі застосування різних НРФП. Таким чином, уроджена $€ \mathrm{H}$ у дітей не $є$ повноцінною в анатомічному і функціональному відношенні.

Таблиця 2

Середні значення основних параметрів при сцинтиграфії нирок

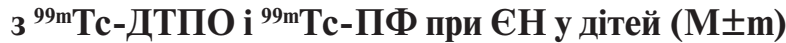

\begin{tabular}{|l|c|c|c|}
\hline \multicolumn{1}{|c|}{ Параметри } & $\begin{array}{c}\text { Середні значення при } \\
\text { ДТПО-сцинтиграфії } \\
\mathbf{( n = 3 1 )}\end{array}$ & $\begin{array}{c}\text { Середні значення при } \\
\text { ПФ-сцинтиграфії (n=20) }\end{array}$ & $\begin{array}{c}\text { Контрольна група } \\
\text { (n=15) }\end{array}$ \\
\hline ШКФСт (мл/хв) & $86,0 \pm 4,8^{* *}$ & $73,5 \pm 4,1^{* *}$ & $119,6 \pm 7,3$ \\
\hline Тмах (хв) & $4,2 \pm 0,7$ & $6,5 \pm 1,3^{*}$ & $3,8 \pm 0,1$ \\
\hline Е20 (\%) & $41,0 \pm 3,7^{* *}$ & $37,0 \pm 4,7^{* *}$ & $86,8 \pm 1,4$ \\
\hline
\end{tabular}

* - відміна між дослідженою групою і контролем вірогідна, $\mathrm{p}<0,05$

** - відміна між дослідженою групою і контролем вірогідна, $\mathrm{p}<0,001$ 
Фільтраційна здатність $\mathrm{EH}$ була також збільшеною порівняно з умовно здоровою ниркою. Найбільші відхилення від норми у дітей 3 $\mathrm{EH}$ мав параметр екскреторної здатності - $\mathrm{E}_{20}$, який вірогідно відрізнявся від значень норми $(\mathrm{p}<0,001)$ і мав відсоток відхилень в межах $110 \%$ тобто трохи більше ніж у 2 рази. Такі дані підтверджуються тим, що у 16 хворих $(53,3 \%)$ був відсутнім параметр Т1/2мах. У цих хворих при аналізі ренограми був зафіксований паренхіматозний (13 хворих, 81,3\%) і обструктивний типи (3 хворих, 18,7\%) ренограми. Візуалізація розширеної миски при $\mathrm{EH}$ у дітей спостерігалася у 8 хворих (26,7\%). Аналіз окремої функції паренхіма-миска підтверджував, що у хворих з $\mathrm{EH}$ функція нирок страждає за рахунок затримки РФП в чашково-мисковому комплексі (ЧМК) і паренхімі.

Таким чином, можна зробити висновок, що $\mathrm{EH}$ працює в посиленому режимі, незважаючи на збільшення іiї розмірів, а відповідно і площі. Так, вертикальний розмір $\Theta H$ був в межах 11,0 $\pm 1,5$ см при нормі $8,0 \pm 0,5$ см $(\mathrm{p}<0,05)$, а гори- зонтальний $-5,5 \pm 0,7$ см при нормі $4,0 \pm 0,3$ см $(\mathrm{p}<0,05)$. Таким чином, при дослідженнях 3 ДТПО і ПФ визначені дані про недостатність адаптаційних процесів в $\mathrm{EH}$ у цієї категорії хворих.

Більш інформативним параметром збільшення $\mathrm{EH} є$ площа сцинтиграфічного зображення. У всіх хворих цей параметр вірогідно відрізнявся від значень норми і мав розмах від 47,5 до 86,4 cм$^{2}$. Площа $\Theta H$ в групі дітей з уродженою патологією була в межах 74,0 $\pm 3,0 \mathrm{~cm}^{2}$. В цій групі хворих площа $\mathrm{EH}$ перевищувала значення норми на $56 \%$.

При дослідженнях з канальцевими РФП 99m Тс-ЕЦ та ${ }^{99 m}$ Тс-МАГЗ спостерігалось вірогідне уповільнення окремого ЕНП $\mathrm{EH}$ і екскреторної здатності (табл. 3). Так, окремий ЕНП збільшувався в 2 рази, а ЕНПСт був зменшений на $25 \%$, але залишався на досить високому рівні. Секреторна ємність $€ \mathrm{H}$ збільшувалась, що свідчило про уповільнення внутрішньо ниркового транспорту РФП.

Таблиця 3

\section{Середні значення основних параметрів при сцинтиграфії нирок} $3^{99 \mathrm{~m}}$ Тс-ЕЦ ${ }^{99 \mathrm{~m}}$ Тс-МАГЗ при ЕН у дітей (M $\left.\pm \mathrm{m}\right)$

\begin{tabular}{|l|c|c|c|}
\hline \multicolumn{1}{|c|}{ Параметри } & $\begin{array}{c}\text { Середні значення при ЕЦ- } \\
\text { сцинтиграфії } \\
(\mathbf{n}=10)\end{array}$ & $\begin{array}{c}\text { Середні значення при } \\
\text { МАГ3-сцинтиграфії } \\
\mathbf{( n = 1 5 )}\end{array}$ & $\begin{array}{c}\text { Контрольна група } \\
\text { (n=15) }\end{array}$ \\
\hline ЕНПСт (мл/хв) & $602,0 \pm 55,9^{*}$ & $690,2 \pm 40,1^{*}$ & $801,5 \pm 98,1$ \\
\hline Тмах (хв) & $4,2 \pm 0,4^{* *}$ & $4,7 \pm 0,9^{* *}$ & $3,0 \pm 0,3$ \\
\hline Т1/2мах (хв) & $16,6 \pm 1,2^{* *}$ & $11,9 \pm 1,3^{* *}$ & $8,0 \pm 1,0$ \\
\hline Е20 (\%) & $58,9 \pm 2,9^{* *}$ & $65,5 \pm 4,6^{* *}$ & $90,2 \pm 4,2$ \\
\hline
\end{tabular}

* - відмінність між дослідженою групою і нормою вірогідна, $\mathrm{p}<0,05$

** - відмінність між дослідженою групою і нормою вірогідна, $\mathrm{p}<0,001$

Таким чином, при дослідженнях з канальцевими НРФП визначені значущі коливання ЕНП, що свідчили про недостатність адаптаційних процесів в $\mathrm{EH}$ у цієї категорії хворих. Площа сцинтиграфічного зображення в середньому по групі складала $51,1 \pm 8,0 \mathrm{~cm}^{2}$. 3начущі відмінності мав параметр Тмах $\mathrm{EH}$, що свідчило про зменшення секреторної ємності. Екскреторна здатність $\mathrm{EH}$ була значно уповільнена і малі відхилення в межах $65-70 \%$ в бік погіршення.

При аналізі даних сцинтиграфії $3{ }^{99 \mathrm{~m}} \mathrm{Tc}$ ДМСО (табл. 4) у хворих з $Е Н$ третя експонента ренограми і період напівочищення крові мали лише тенденцію до збільшення. Параметри, що характеризували розподіл і накопичення РФП в нирках вірогідно відрізнялись в бік збільшення від параметрів нормальної нирки. Тобто, такий стан речей також свідчив про те, що $\mathrm{EH}$ працює в посиленому режимі. Це підтверджує приховану ниркову дисфункцію при оцінці накопичення РФП в печінці. Цей параметр показує, що незважаючи на посилене захоплення ДМСО ниркою є ознаки ниркової недостатності. По відсотку фіксації РФП в нирці можливо зробити висновок, що у дітей при ознаках ниркової недостатності функціонуюча паренхіма працює на задовільному рівні про що свідчать параметр очищення крові і третя експонента ренограми. 
Сцинтиграфічні параметри морфофункціонального стану

ЕН у дітей $3^{99 m}$ Тc-ДМСО $(\mathrm{M} \pm \mathrm{m})$

\begin{tabular}{|l|c|c|}
\hline \multicolumn{1}{|c|}{ Параметри } & \multicolumn{1}{|c|}{$\begin{array}{c}\text { Сдина нирка } \\
(\mathbf{n = 1 5 )}\end{array}$} & $\begin{array}{c}\text { Контрольна група } \\
(\mathbf{n = 1 5 )}\end{array}$ \\
\hline 3 експонента ренограми & $16,9 \pm 1,9$ & $15,6 \pm 1,2$ \\
\hline Т1/2 крові, хв & $42,6 \pm 6,9$ & $36,6 \pm 1,6$ \\
\hline КДП 5 хв & $52,6 \pm 3,6^{* *}$ & $35,4 \pm 2,2$ \\
\hline КДП 20 хв & $65,2 \pm 5,5^{* *}$ & $41,0 \pm 3,0$ \\
\hline КДП 30 хв & $70,4 \pm 6,2^{* *}$ & $43,0 \pm 2,0$ \\
\hline КДП 180 хв & $85,8 \pm 5,5^{* *}$ & $49,0 \pm 1,0$ \\
\hline \% включения до 30 хв & $11,2 \pm 2,8^{* *}$ & $5,3 \pm 0,6$ \\
\hline \% включения до 180 хв & $18,0 \pm 4,9^{*}$ & $8,5 \pm 0,4$ \\
\hline КДП печінки 5 хв & $47,4 \pm 3,6^{* *}$ & $31,2 \pm 2,4$ \\
\hline КДП печінки 20 хв & $34,7 \pm 5,5^{*}$ & $23,5 \pm 2,7$ \\
\hline КДП печінки 30 хв & $29,6 \pm 6,2^{*}$ & $18,2 \pm 2,1$ \\
\hline КДП печінки 180 хв & $14,2 \pm 5,5^{* *}$ & $6,5 \pm 0,8$ \\
\hline
\end{tabular}

* - відмінність між дослідженою групою і нормою вірогідна, $\mathrm{p}<0,05$

** - відмінність між дослідженою групою і нормою вірогідна, $\mathrm{p}<0,001$

При аналізі розподілу РФП (табл. 5) в $\mathrm{CH} \mathrm{у}$ 66 дітей спостерігався рівномірний його розподіл (73,3\%). Дифузний нерівномірний розподіл зафіксований у 14 хворих $(15,6 \%)$, а вогнищевий нерівномірний у 10 хворих $(11,1 \%)$. Це свідчило про те, що в $Є$ Н кількість паренхіми $€$ недостатнім більш ніж у третини хворих.
Ділянки ураження паренхіми фіброзними змінами реєструвалися у верхньому або нижньому полюсі нирок (6 хворих, 6,7\%) і рідше по зовнішньому контуру у вигляді крайових дефектів середнього сегменту (4 хворих, 4,4\%) і по всій паренхімі (14 хворих, 15,6\%).

Варіанти розподілу РФП в СН у дітей

\begin{tabular}{|l|c|c|}
\hline \multirow{2}{*}{ Варіанти розподілу РФП } & \multicolumn{2}{|c|}{ Кількість хворих з єдиною ниркою (n=90) } \\
\cline { 2 - 3 } & Абс. & \% \\
\hline Інтенсивно рівномірний розподіл & 47 & 52,2 \\
\hline Відносно рівномірний розподіл & 18 & 20,0 \\
\hline Рівномірно знижений розподіл & 1 & 1,1 \\
\hline Дифузний нерівномірний & 14 & 15,6 \\
\hline Вогнищево нерівномірний & 10 & 11,1 \\
\hline Всього & 90 & 100 \\
\hline
\end{tabular}

При $\mathrm{EH} \mathrm{у} \mathrm{дітей} \mathrm{всі} \mathrm{РФП} \mathrm{мали} \mathrm{майже} \mathrm{одна-}$ кову діагностичну значимість, яку визначали по кількості відмінностей параметрів від параметрів умовно нормальної нирки (рис. 1). Так, відхилення для $99 \mathrm{~m}$ Тс-ДТПО складало 0,72 , для

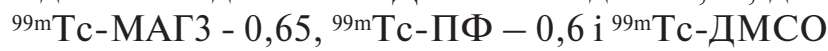
- 0,53. Найменш значушим був ${ }^{99 m}$ Тс-ЕЦ відхилення для якого дорівнювало лише 0,47 . 


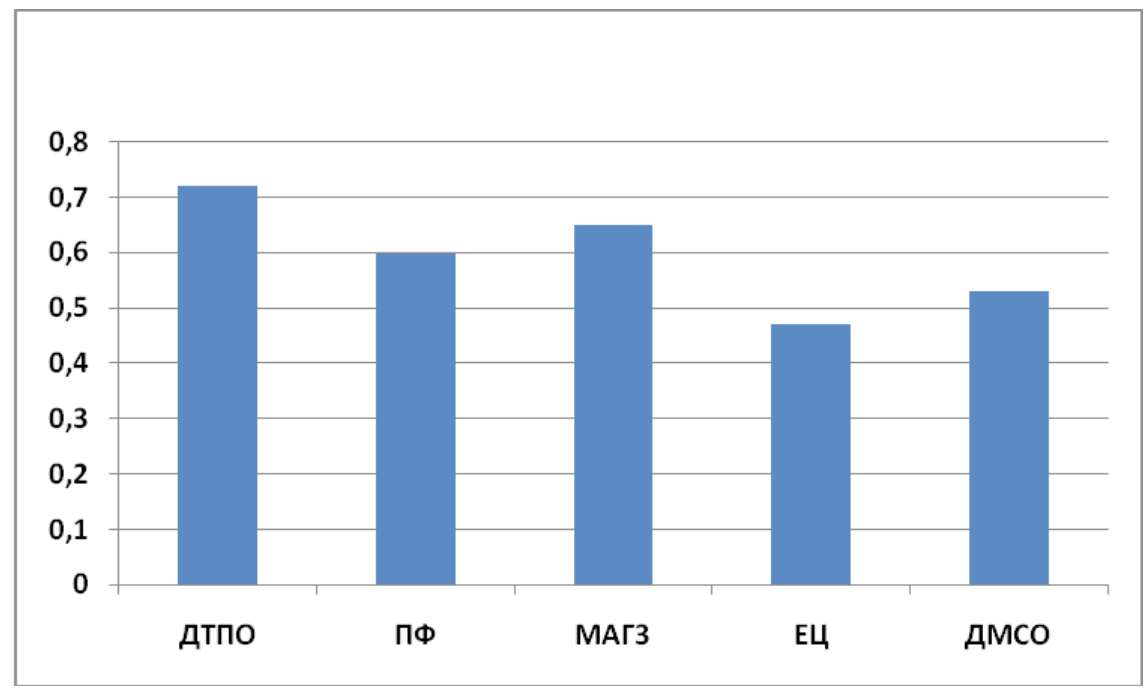

Рис. 1. Оцінка інформативності препарату для генеральної сукупності пацієнтів при єдиній нирці

Таким чином, узагальнюючи отримані результати можливо зробити висновок, що наявність $\mathrm{CH}$ і особливості ії функціонування можливо визначити будь яким НРФП. Основними сцинтиграфічними критеріями $\mathrm{CH} є$ візуалізація однієї нирки протягом всього дослідження; уповільнення параметрів ниркової гемодинаміки, збільшення розмірів $\mathrm{EH}$, збільшення ШКФСт і ЕНПСт на 25-40\%, уповільнення екскреторних процесів. При первинних дослідженнях доцільно використовувати ${ }^{99 \mathrm{~m}}$ Тс-ДТПО або ${ }^{99 \mathrm{~m}} \mathrm{Tc}-П Ф$, при порушенні екскреторних процесів і затримці РФП в мисках повторні дослідження потрібно проводити з канальцевим РФП, а при наявності змін в сечі, ознаках ПН доцільно використовувати ${ }^{99 \mathrm{~m}}$ Тс-ДМСО.

\section{ВИСНОВКИ:}

1. $\mathrm{EH} \mathrm{у} \mathrm{дітей} \mathrm{функціонує} \mathrm{в} \mathrm{посиленому} \mathrm{режимі}$ про що свідчить порушення всіх функціональних параметрів відносно до умовно здорової нирки.

2. Нормальними параметрами для $\mathrm{EH}$ у дітей $€$ збільшення iï розмірів в середньому на 2-3 см і площі сцинтиграфічного зображення на 30$40 \%$.

3. Порушення екскреторної здатності $\mathrm{EH}$ пов'язані з гіпертрофією нирки, недостатньою кількістю функціонуючих нефронів, порушеннями ниркової гемодинаміки i, як слід, збільшенням часу внутрішньо ниркового транзиту РФП.

4. Основними параметрами в динамічному спостереженні за функцією $Є Н$ у дітей $є$ ШКФСт і ЕНПСТ.

5. Для визначення структурно-функціональних змін в $\mathrm{EH} \mathrm{у} \mathrm{дітей} \mathrm{можливо} \mathrm{застосовувати}$ любий нефротропний РФП, а більшу перевагу потрібно віддавати клубочковому ${ }^{99 \mathrm{~m}} \mathrm{Tc}$ ДТПО.

\section{ЛІТЕРАТУРА:}

1. Возіанов $О$. Ф. Вроджені вади сечових шляхів у дітей / О. Ф. Возіанов, Д. А. Сеймівський, В. С. Бліхар. - Тернопіль : Укрмедкнига, 2000. $220 \mathrm{c}$.

2. Зарипов M. M. Распространенность патологии единственной почки и ее этиологическая структура у детей 0-17 лет / М. М. Зарипов, Н. Т. Тихомирова // Материалы Конгресса педиатров-нефрологов России (2-4 декаб. 2003 г.). - СПб., 2003. - С. 110-111.

3. Клиническая нефрология детского возраста / А.В.Папаян, Н.Д.Савенкова. С.-Петербург, 1997. - 718c.

4. Кундін В.Ю. Особливості проведення методик та обробки діагностичної інформації при сцинтиграфічних дослідженнях сечовидільної системи в дітей / В.Ю.Кундін, М.О. Ніколов // УРЖ.- 2002.№4.-430-434.

5. Кундін В.Ю. Динамічна реносцинтиграфія в нефрологічній практиці / В.Ю.Кундін // «Актуальні проблеми нефрології. Збірник наукових праць (випуск 8). Київ, 2003.- С.64-71.

6. Находкина И.В. Функциональное состояние единственной почки у детей по результатам динамической нефросцинтиграфии и пробы с капотеном : автореф. дис. на соискание уч.степени канд. мед.наук: спец.14.00.19 - лучевая диагностика, лучевая терапия / И.В.Находкина. - М., 1999. $28 \mathrm{c}$.

7. Променева діагностика : [в 2 т.] / Г.Ю.Коваль, Д.С.Мечев, Т. П. Сиваченко [та ін.] ; за ред. Г. Ю. Коваль.- К. : Медицина України, 2009. T. 1. $-832 \mathrm{c}$.

8. Руководство по урологии / под ред. Л. Липшульца, И. Клаймана. - СПб. : Питер, 2002. - 564 с.

9. Piepsz A. Radionuclide studies in paediatric nephrourology / A.Piepsz // Eur. J. Radiol.- 2002.- Vol.43.P.146-153. 